\title{
Research at Small Canadian Universities
}

\section{MICHAEL OWEN*}

\begin{abstract}
Research in Canadian universities has received much attention in recent years. Governments and research councils have encouraged greater communication between industry and university researchers. Recently research councils, university administrators, and university faculty have focused their attention on improving the research environment in small universities. In the paper, the author outlines some of the issues that are deemed important to the conduct of research by faculty at small universities in English Canada. The paper is based on six years' experience as a research administrator at a small university, and on a survey of research administrators, including vice-presidents academic and deans of graduate studies who had research as part of their daily responsibilities. The research was presented initially at the 1988 CAURA meetings. In this paper, some of the issues that are important to the conduct of research at small Canadian universities are outlined.
\end{abstract}

\section{Résumé}

La recherche effectuées dans les universités canadiennes a reçu beaucoup d'attention ces dernières années. Les gouvernements et les Conseils subventionnaires ont fait la promotion de liens plus étroits entre chercheurs industriels et chercheurs universitaires. Récemment, des efforts particuliers ont été faits par les divers organismes pour améliorer l'environnement de recherche dans les petits établissements. Cette communication soulève les problèmes particuliers rencontrés par les chercheurs des petits établissements canadiens de langue anglaise. Elle s'appuie sur les six années d'expérience de l'auteur en tant que gestionnaire de la recherche dans un établissement de petite taille, de même que sur une enquête réalisée auprès d'administrateurs universitaires incluant les vice-présidents académiques et les doyens des études avancées ayant la responsabilité administrative de la recherche. Les résultats de cette étude ont été présentés en 1988 au colloque de l'Association des administrateurs de la recherche universitaire ( $A C A R U)$.

* Formerly of Athabasca University, 1989-1991; now Director, Research Services,

University of Saskatchewan 


\section{Introduction}

Do faculty at small Canadian universities encounter more barriers in their pursuit of research funds, especially from national research councils, than do their colleagues in the large research or medium size institutions? How may the administration in small universities assist faculty in overcoming these barriers and other barriers to scholarly activities? Are there strategies by which small universities can enhance the research climate in their institutions or build a tradition of high quality scholarship, i.e., the promotion of excellence in research, publication and teaching? Are small universities suitable places in which high quality scientific research can be promoted? These and other questions have been addressed by university research administrators at five national conferences on research at small universities since 1986.'

\section{The Debate}

The quality of the discussion about support for scholarly activities of academic staff at Canada's small universities has progressed little in the last decade. The Canada Council's Consultative Group on the Needs of Scholars at Small Universities (Canada Council, 1977) set the tone for most studies, reports or editorials and national conferences. Since 1977, Ingalls (1982), Perkin (1985), Biron (1985), and Bélanger (1989), with some modifications, have reiterated the Canada Council's findings: the research climate at smaller institutions is constrained by heavy teaching loads, inadequate equipment, lack of graduate students, and the difficulties of attracting high quality faculty to smaller institutions. $^{2}$

Few question the desirability of high quality scholarship at small universities. Newbould (1989) argues that implicit in the debate over funding for research at small universities is the desire of some to relegate the role of small universities to undergraduate teaching. This, Newbould asserts, underlays the proposal that George Connell, then President of the University of Toronto, presented in his articles in the Globe and Mail (Connell, 1989). More recently, Research at Canadian Universities: The Issues, a report of the Committee of University Research of the Royal Society of Canada (1989), while noting the uneven distribution of sponsored research funds among Canadian universities, raised, however obliquely, the issue of differentiating between "research intensive and 'teaching' universities." The assumption of both Connell and the Royal Society is that the small institutions would become exclusively teaching institutions. 
Newbould roundly denounces such ideas as heresy and affirms the essential link between research and teaching as a core principle of universities.

If research, the scholarly and systematic search for new and the testing of existing knowledge, and teaching, the systematic dissemination of knowledge, are two sides of one coin, the debate should not focus on whether faculty at small universities should participate in research, but on how to maintain and build up the research enterprise at small universities. Bélanger (1989) argues for a targeting of research at small universities to "a few lines" that would be interdisciplinary. Collier (1989) sees "interdisciplinary research and thinking" as "one of the advantages of being [a faculty member] at a small university..." Bélanger's argument is based on an "entrepreneurial" model that suggests small universities should husband and concentrate their resources so that each might have a small number of high quality products for a specific niche in the marketplace. Collier sees interdisciplinary research opportunities as growing out of the inevitable exchange of ideas between diverse staff within an intimate institution. David Pink (University Affairs, 1990) advised researchers at small universities to consider the formation of research teams or networks of researchers, usually interdisciplinary, as one strategy for encouraging research and for obtaining external research funding.

\section{The Key Issue: A Positive Research Climate}

While these suggestions are exciting and demand further exploration, this paper focuses on the key issue identified by Ingalls (1982), Perkin (1985), and Bélanger (1989), viz., how may small universities foster the development of a more productive and positive research climate among academic staff? The way in which a positive research climate is created and the importance of a vibrant research climate in small universities were stated succinctly in the Canada Council report (1977).

A promising research climate is created by an active group of researchers with a functioning infrastructure (research assistants, secretaries, data sources), ideally in more than one discipline. The presence of visible on-going research on campus stimulates interest in research and provides the opportunity for spin-off work or hooking on to existing work. Furthermore, it adds a dimension to the academic activity of the university that would otherwise be lacking to a large degree: with ongoing research, not only can theory be taught 
but methodology can be demonstrated.

The creation of a "promising research climate" is not a simple task. Since 1986, in a series of national conferences on research at small universities, research administrators, academic staff, and representatives of the Social Sciences and Humanities Research Council (SSHRC) and the Natural Sciences and Engineering Research Council (NSERC) have searched for an understanding of the barriers to the development of a positive research climate at small universities and strategies for overcoming these barriers. Participants at these conferences have debated ways to overcome the constraints of heavy teaching loads, inadequate equipment, lack of graduate students, difficulties of attracting high quality faculty, and the relationship between participation rates and success rates in SSHRC and NSERC competitions.

In his case study of Mount Saint Vincent University, Halifax, N.S., Ingalls (1982) identified seven major constraints on research productivity by academic

Table 1

Constraints on Research Activity

\begin{tabular}{lcc}
\hline Restraint & Rank & Mean \\
\hline Heavy teaching loads & 1 & 1.6 \\
Inadequate research facilities & 2 & 2.9 \\
Few graduate students & 3 & 3.5 \\
Little internal funding & 4 & 3.7 \\
Lack of research tradition/orientation & 5 & 4.1 \\
Inadequate secretarial support & 6 & 4.3 \\
Limited contact with others in field & 7 & 4.7 \\
\hline
\end{tabular}

Note

The scores attributed to the items were: 1 (strongest restraint) to 7 (weakest restraint). These scores were then compiled and divided by the sample size for the mean score.

staff at small universities. In 1987, the writer surveyed research administrators at 25 small Canadian universities and requested that they rank order these constraints. The data are summarized below.

Heavy teaching loads and the number of student contact hours are perceived to be the greatest impediments to research at small universities. Bélanger (1989) confirmed that undergraduate teaching loads of faculty at small universities are $25 \%$ greater than those of colleagues at larger universities, although the 
demands created by the supervision of graduate student were substantially less. Moreover, Bélanger intimates that the more competent faculty at small universities are burdened with more administrative and other duties than colleagues at larger universities where these demands may be shared among a larger pool of qualified individuals. As comforting as Bélanger's data are for those who have argued consistently that faculty at small universities are overburdened by teaching responsibilities relative to their colleagues at the larger universities, Adair and Davidson (1984), in their study of research activity of university-based social scientists, found that social scientists at universities, independent of size, perceived lack of time, heavy teaching loads, and committee work as impediments to research. If humanists and social scientists at larger universities perceive these same constraints as affecting negatively their scholarly pursuits (research being one component of scholarship), then it is probable that other factors in the institution's culture or infrastructure may place additional barriers in the path of researchers at smaller institutions.

It is intriguing that "isolation" was ranked on average lowest on the scale of constraints to research by research administrators, most of whom were also active scholars. Bélanger (1989) implies that two barriers faced by faculty at small universities are geographical isolation from their disciplinary peers and disciplinary isolation from their colleagues within the institution. These two barriers exert potentially the greatest constraints on research at small universities, especially with some of the more specialised disciplines and sub-disciplines, yet research administrators were not unanimous in their ranking of the criterion of isolation. Although a third of the sample ranked "isolation" as the second most important constraint, one half of the administrators ranked this constraint as sixth or seventh on the scale. While it is true that faculty at small universities are often one of two or three members within a discipline, it is the perception of isolation more than its actuality that hinders research activity. Faculty at small universities may covet the number of members in similar departments at larger universities without considering the often pervading sense of anomie and intra- and interdisciplinary rivalries within those departments. It is not always true that a "critical mass" of researchers within a department corresponds to a large number of faculty in one discipline, especially given the large variety of narrow specializations within most disciplines.

Geographic isolation is a relative issue. Faculty at University College of Cape Breton, Brandon University or Lakehead University are isolated in comparison to their colleagues at University of Winnipeg or Wilfrid Laurier 
University. However, being within close geographic proximity to disciplinary colleagues does not always reduce the perceived constraint of disciplinary isolation within one's own institution. To have disciplinary colleagues "down the road" may actually increase one's sense of isolation when one is struggling to make one's research requirements understood by one's institutional colleagues and senior administrators.

One solution to the perceived barriers posed by geographic and disciplinary isolation urged upon faculty members at small universities is to use isolation as an opportunity for interdisciplinary research. This opportunity arises from the familiarity of faculty with their colleagues' work in other disciplines and may be enhanced by collaborative research teams with faculty at nearby institutions which, together, may more than compensate for the smaller number of colleagues in one's own discipline (Bélanger, 1989; Collier, 1989). This emphasis on interdisciplinary research should not be dictated by the university, but should grow out of interaction between faculty. Both Belanger and Pink argue that interdisciplinary research should be facilitated by the university community assessing what it can do well and then concentrating efforts in those few areas.

The inadequacy of research facilities, particularly in the natural sciences and social sciences that require laboratory space (e.g., psychology) or heavy use of computer resources ( e.g., social history), is recognized as a major constraint on research by faculty, university administrators and granting councils. Laboratories, technicians, and research assistants required by researchers in the natural sciences and some of the social sciences place heavy demands on the operating budgets of small universities. Yet, such expenditures are essential not only as demonstrations of the university's on-going commitment to research but also, since they are often required before faculty can apply successfully to external granting agencies for operating funds, to support their research programs. ${ }^{3}$

There are, as well, structural or systemic changes that may be implemented to overcome perceived and actual barriers to scholarly activities. In spite of the rhetoric of university presidents, small universities have yet to confront adequately the issues of research infrastructure and the building of a positive research climate. University administrators and faculty often lament the poor "research culture" at their institutions, yet acknowledge institutional shortcomings, including hiring practices, promotion and tenure procedures, and university infrastructure (including teaching loads, committee duties, and inadequate library facilities and equipment) that contribute to this environment. These administrators and faculty recognize that the "research climate" of their 
institutions could be promoted in ways that do not overburden the budgets or undermine the academic morale of the institutions.

\section{Overcoming Barriers}

(1) Internal research funds:

To overcome these barriers (real and perceived) to a positive research climate in small universities, the senior administration must demonstrate its commitment to research in word and in deed. One of the most effective and visible ways to do so is to allocate funds from the internal budget for research. ${ }^{4}$ In an effort to see whether small universities support research in this manner, data were collected on internal research budgets of small universities in Canada. While all small universities do allocate funds for research from central budgets, these budgets (1987) ranged from $\$ 17,500$ to over $\$ 150,000$. Stated in another way, internal research budgets, if allocated on a per capita basis, would have provided from $\$ 115$ to $\$ 750$ per faculty member. Since these funds are distributed on a competitive basis by peer review of research proposals and not on a per capita basis, it is clear that, even supplemented with the general research grants from the Social Sciences and Humanities Research Council and the Natural Sciences and Engineering Research Council and any funds from the two councils' supplemental programs for small universities, available funds are able to support only a few research projects. ${ }^{5}$ In their annual meetings, research administrators unanimously endorsed the view that such internal research funds are essential to the promotion of a research culture, especially for new faculty members. All argue that these funds should provide faculty with experience in the preparation of research proposals. Faculty who have worthy research proposals, as judged by an internal university peer review, should receive "seed funding" from this pool. Thus, the internal research fund should provide only seed money, enough to get the research underway and to assist the faculty member in developing a "track record." Furthermore, these funds are especially important to new faculty members who require an opportunity to get started on research projects, and to develop the research base for applying for external research grants and contracts.

The success rate of faculty members who have held internal grants in national competitions for research funds has not been discussed directly at the various national conferences nor were such data collected as part of the 1987 survey. Indeed, research administrators and faculty themselves debate whether colleagues who acquire internal research funds actually employ them for the, 
purpose of developing research ideas to the point where they can apply for external research grants. Experience, and preliminary research on linkages between internal research grants and applications to external agencies by faculty at a large Canadian university, suggest that only a small number of faculty at small universities and who hold internal research grants actually apply to external granting agencies for funds to extend internally funded research projects, although those who do are often successful. No discernible relationship appears to exist between the availability of internal research funds and success in external competitions. ${ }^{6}$ Some have suggested that internal research budgets, while important to the promotion of a research culture, at times, may undermine the goals of these budgets if they are perceived as a crutch for academic staff who, not confident in their own abilities, do not apply for external funds.

(2) Active Researchers:

Perhaps the most important variable in the development and maintenance of a research climate at a small university is the presence on staff of successful researchers (Canada Council, 1977). While some faculty members deny their competitive spirit, the presence of a colleague who has a multi-year research grant from a national granting council or a-series of published research articles in prestigious journals is a serious spur to other faculty members. Research grant or contract recipients provide one bench-mark from which faculty (and deans) measure the research acumen of their colleagues. The real benefits of these grantholders to the research environment of the institution include: advice to other faculty who are preparing grant applications to the same granting agency, evidence that faculty from the institution can obtain external research funds, especially when the grant is obtained in competition with faculty from across the nation, and demonstration that the administration of the university does support the research enterprise. ${ }^{7}$

In addition, universities that have post-doctoral fellows, research associates, or externally-funded chairs on staff and/or externally funded research centres demonstrate to faculty that scholarship is a priority. Fellows devote most of their time to research projects, usually in association with a faculty member, and to the preparation of research reports and scholarly articles for journals. Although support for post-doctoral fellows is acquired through external competition, faculties and departments contribute substantial (in-kind) resources and universities often obtain matching funds from the private sector to support these fellows. More important, however, is the commitment that fellows have to research - they are often young, energetic, and at the 'cutting edge' of their 
field. Their contribution to the research climate of the university is self-evident: they are productive; they add to their mentors' research productivity; and they increase the visibility of research in the department, faculty and university.

(3) Research Infrastructure:

The research infrastructure of any university requires up-to-date laboratory equipment and computing facilities, research libraries, an on-going programme of staff development and research seminars, visiting scholars, and an informed research administration. Up-to-date equipment and computing facilities are essential. A good library with adequate funding (although not necessarily a specialised research library) is an asset. An informed research administration office can be one of the most important assets in the promotion of research at a small university.

Other forms of internal support essential to the development and cultivation of a positive research climate that are taken for granted by faculty members at medium and large universities are often problematic at smaller universities. These include financial support for laboratory assistants, including technicians, full- or part-time lab assistants, senior undergraduate or graduate student assistants, etc.; adequate laboratory facilities; up-to-date, specialised laboratory equipment; and up-to-date computing services. These services are as important to the development of a research culture as an internal research budget. Moreover, since these are expensive services and have on-going budget requirements, their provision demonstrates to faculty that the university administration is serious in its promotion of research. Yet, it is not unusual for faculty members at small universities to reshape their research to accommodate the lack of sophisticated research equipment, the absence of graduate student assistants or specially trained technicians, or necessary computing services. With the reduction of available funding for research equipment from university, government and granting agencies, researchers become innovative in carrying out their research, if not a little frustrated as well.

(4) Research Administration:

Finally, an important component of the research environment at small universities is the presence of a research administrator (Ingalls, 1982; Gogan, 1985) and a "Senate" research committee. ${ }^{8}$ A full-time research administrator, that is, an individual who has the administration of research as her/his primary responsibility, is rare at small institutions. All small universities have someone who has nominal responsibility for research administration. The 1987 survey reported 
that 47 percent ( 7 of 15) of administrators with the administrative responsibility for research had this responsibility added to other major and usually more pressing responsibilities. It is not uncommon for the academic vice-president, the dean of graduate studies, or the administrative assistant to a vice-president or the president to be responsible for the administration of research. Attention to research administration, thus, becomes diluted inevitably by other responsibilities. While all acknowledge the benefits to the institutions of dedicated research administrators, fewer than one half of the small universities are able to provide adequate resources for the assignment of one full-time professional to research administration.

While scarcity of resources is an obvious explanation for this gap in the administrative structure, another is the lack of conclusive data that demonstrates clearly the linkages between a professional staff member with sole responsibility for research administration and the level of external research funds attracted by the university. Anecdotal statements by researchers support the value of the work of these individuals where they exist. The value of these individuals is demonstrated by the success that small universities with only part-time administrators have in attracting external grants and contracts. Although much of the success can be attributed to the research orientation of the faculty or the location of a "research centre" on campus, rather than to the presence of a research administrator, Ingalls' case study of Mount Saint Vincent University provides evidence that a research administrator is an important factor in determining the amount of research funds attracted by the university. It is essential that detailed research on productivity, as measured by research grants and contracts, publications, etc., be conducted on a wide spectrum of small universities to determine the impact of the appointment of a research administrator.

The arguments for the appointment of a research administrator are many. Research administrators serve as a focal point for the research enterprise. These individuals are in contact with personnel in granting agencies, have a broad knowledge of available resources, and are skilled in writing and in assessing grant applications. Their contacts with research granting agencies and their familiarity with the procedures of granting councils provide benefits to faculty, such as, at the very minimum, up-to-date information on application deadlines, procedures, and budgets. The research administration staff, if their time is devoted primarily to research administration, can be a great service to faculty, especially by locating sources of research funds for faculty and assisting faculty in the application procedures with both the private and the public sectors. Moreover, if this office also is responsible for publicizing research 
achievements of faculty, the higher profile given to research in the university can be very beneficial internally and externally. Faculty perceive these persons as resources and aids to their scholarly activities rather than as gatekeepers.

\section{Concluding Comments}

Any discussion of research infrastructure at small universities is "academic" unless one can demonstrate that changes to the institution's infrastructure, including the appointment of a research administrator, add to the research climate or to the willingness of faculty to do research, to apply for external research grants and contracts, to support their research activities, and to publish the results of their research, as well as to integrate their research into their teaching. In the case of the presence on staff of a dedicated research administrator, measures or instruments are inadequate, since the success of research administrators is determined not by the administrators, but by the faculty. The research climate of an institution is set more by the faculty involved or not involved in research than it is by the administration.

Faculty at small Canadian universities are vigorous researchers. While natural scientists at small universities obtain a greater number of research grants and contracts than do their colleagues in the social and human sciences, they do not enjoy a success rate as great as their colleagues in larger universities in national competitions (NSERC, 1989). ${ }^{9}$ Similarly, social scientists and humanists at small universities apply less often to SSHRC and experience less success than do their colleagues at larger universities (SSHRC, 1989a). As a result, it is more likely that faculty at small universities fund their research by small grants from internal university budgets or, similar to humanists and social scientists at larger universities, simply do unfunded research, that is, research that is supported from professional development funds or the faculty member's own resources (Adair and Davidson, 1984). Therefore, by comparison with colleagues at larger universities, researchers at small universities appear to be underfunded. How this underfunding reflects on research productivity at small universities, compared to research productivity at medium size and large universities, needs to be examined in greater detail. ${ }^{10}$

There are many excellent scientists in both the natural sciences and the human sciences at small institutions who deserve support. If universities implement internal procedures to encourage and foster a research climate - by deed as well as by word - and if the research councils consider alternative strategies to fund research at small universities, then it is probable that research 
productivity at small universities would expand greatly, both in quality and in scope. That there is much excellent research being conducted at small universities cannot be denied.

\section{Notes}

1 The first national conference on research at small universities, held at Saint Mary's University, Halifax, N.S., in 1986, focused on research in the social sciences and humanities. The second national conference, held at Laurentian University, Sudbury, Ont., in 1987, discussed research in the natural sciences. The third national conference, held at Brandon University, Brandon, Man., considered ways to improve the research climate at small universities. The 1989 national conference, held at Lakehead University, Thunderbay, Ont., focused on the relationships between small universities and the two major national granting councils and the efforts of universities to improve research opportunities for academic staff. The most recent national conferences were held at Acadia University, Wolfville, N.S., and the University of Lethbridge, Alberta.

2 In an effort to understand the pervasiveness of these constraints and to seek out strategies to overcome these barriers to research productivity at small universities, a questionnaire was mailed to research administrators at twenty-five small Canadian universities in the autumn of 1987. Thirteen universities completed the questionnaire and provided information on research administration and infrastructure, policies, issues, and research grant and contract income for their institutions. In addition, data were gleaned from an informal survey of research infrastructure conducted for the 1988 national conference and from reports on scholarship and research at these universities. This data, notes taken at the national conferences, and six years of experience as a research officer at a small university, provided the underpinnings for this report on research at small universities.

3 For example, library resources of small universities, designed primarily for undergraduate instructional purposes, cannot and ought not to replicate the holdings of libraries at larger universities (e.g., Alberta, U.B.C., Toronto or Dalhousie). With few exceptions, larger university library facilities are within a two hour drive of most small universities (in the case of faculty who live in the larger centres, somewhat less), and, given the willingness of librarians at small universities to devote relatively large proportions of their operating resources (including staff time) to acquire books, etc., through inter-library loan services and to arrange for faculty borrowing privileges at research libraries, faculty at small universities have relatively good access to research libraries.

4 The funding sources for internal research budgets vary among institutions. Some universities provide the internal research budget from endowment funds (a secure source), others from the regular operating budget (a less secure source), others from a combination of regular operating budgets, general research grants from SSHRC and 
NSERC, research contract overheads, and endowment funds.

5 The internal research budgets are supplemented by the General Research Grant received by most universities from the SSHRC and NSERC. These grants are performance-based (that is the success of an institution's faculty in the national competitions is reflected in the size of the GRG provided to the institution.) The GRGs are employed to support research at an institution: equipment, small research grants, and travel.

6 Preliminary research, conducted while on leave in 1989-90, and experience have suggested that there is little relationship between internal research funds and applications for external grants..

7 Moreover, if a faculty member is on a SSHRC or NSERC grant selection committee, the opportunity for other university faculty to benefit from that individual's knowledge of the workings of the GSCs and the council is tremendous.

8 The work of Senate research committees is not discussed in this paper. The duties of these committees vary greatly from institution to institution. At some institutions, the Senate research committee is primarily a policy formulation body. At others, the committee develops policy and administers the internal research budget and, on occasion, the GRG.

9 The issue of success rates is a complicated one. Since NSERC and SSHRC competitions are peer reviewed, an aura of objectivity surrounds the grant selection committees' (GSC) decisions. However, some researchers and research administrators fear that the GSCs allow other criteria, e.g., the location of the university, the size of the faculty, etc., to inform their decisions. Hence, the perception may be that good science cannot be conducted in small universities. Also, since the budgets of these institutions are only a fraction of that of larger universities, the institutions' contributions to specialized laboratories are necessarily limited. Researchers therefore depend to a much greater extent on external funds to purchase equipment and to sponsor research. These funds, especially at NSERC, are extremely limited, even for the larger "research" universities. The perception, again, perhaps unjustified, is that the small universities are less successful in the equipment competitions because of their size and location.

10 The author acknowledges the demands placed upon the budgets of the national granting councils and applauds the efforts by the administrators of these councils to ensure that their budgets are allocated in a fair and equitable manner. Moreover, the efforts of the councils, especially NSERC, to ensure that new applicants' research programmes are funded deserve commendation.

\section{References}

Adair, John G. \& Davidson, Robert. (1984). Research activity in the social sciences: A review of funding, productivity and attitudes of university-based social scientists. Ottawa: Social Science and Humanities Research Council of Canada. 
Bélanger, Charles H. (1989). University entrepreneurship and competition: The case of small universities. The Canadian Journal of Higher Education,19 (2), 13-22.

Biron, Andre. (1985). Report on the study of the research development program. Ottawa: Natural Sciences and Engineering Research Council of Canada.

Canada Council. (1977). Needs of scholars at small universities: Report of the consultative group on the needs of scholars at small universities. Ottawa: Canada Council.

Collier, Gary. (1989, April). Interdisciplinary research at small universities. Paper presented at the National Conference on Research at Small Universities, Lakehead University, Thunderbay, ON.

Gogan, Niall. (1985). Research administration in Canadian universities. Ottawa: Science Council of Canada.

Gogan, Niall. (June, 1991). Who's on second? Presentation to the Canadian Association of University Research Administrators, Ottawa.

Gaon, Stella, \& von Zur-Meuhlen, Max. (1989). Barriers to management research. Canadian Federation of Deans of Management and Administrative Studies, Working Paper Series, 1989(2).

Ingalls, Wayne B. (1982). Increasing research productivity in small universities: A case study. The Canadian Journal of Higher Education, 12 (3), 59-64.

Natural Sciences and Engineering Research Council of Canada. (1988). [NSERC expenditures - cumulative by institution, 1985-86]. Unpublished table distributed at the National Conference on Research at Small Universities, Brandon, Manitoba.

Natural Sciences and Engineering Research Council of Canada. (1989). Presentation to the 4th national conference on research at small universities. Unpublished report and tables.

Newbould, Iain D.C. (1989). Research at small universities: A case. Paper presented to the National Conference on Research at Small Universities, Lakehead University.

Perkin, J.R.C. (1985). Research in small universities. The Canadian Journal of Higher Education, 15 (3), 1-4.

Research submissions need interdisciplinary focus. (1990, August-September). University Affairs, p. 15.

Social Sciences and Humanities Research Council of Canada. (1989a). Unpublished data on the participation of faculty from small universities in SSHRC competitions.

Social Sciences and Humanities Research Council of Canada. (1989b). Small universities program - Program description.

Social Sciences and Humanities Research Council of Canada. (1989c). Report to the SSHRC on the evaluation study of the aid to small universites program, (executive summary). Prepared by Robert Hanson, Evaluation and Statistics Division, Secretariat General.

Social Sciences and Humanities Research Council of Canada. (1989d). Research grants review committee, final report. Courtney Report. 